J. Clin. Chem. Clin. Biochem.

Vol. 26, 1988, pp. 135-140

(C) 1988 Walter de Gruyter \& Co.

Berlin - New York

\title{
A Comparison of Commercially Available Luminescence Enhanced Enzyme Immunoassays with In-House Non-Radioisotopic Assays for Thyroxine Binding Globulin and Total Thyroxine
}

\author{
By W. G. Wood, Claudia Rohde and Astrid Jacobs
}

Klinische Laboratorien, Klinik für Innere Medizin (Direktor: Prof. Dr. P. C. Scriba), Medizinische Universität zu Lübeck, Lübeck

(Received September 14, 1987/January 7, 1988)

Summary: Commercial luminescence enhanced enzyme immunoassays (Amersham-Amerlite) for thyroxine binding globulin $(\mathrm{TBG})$ and total thyroxine $\left(\mathrm{TT}_{4}\right)$ were compared with the in-house methods $\left(\mathrm{TT}_{4}-\mathrm{Abbott}\right.$ TDx, TBG - Immunoluminometric Assay (ILMA)).

The experimental groups consisted of 108 healthy euthyroid blood donors, 165 non-selected thyroid outpatients, 44 tumour bearers and 84 haemodialysis patients.

Total thyroxine/thyroxine binding globulin quotients were constructed as an index of thyroid function.

The luminescence enhanced enzyme immunoassays were precise (interassay coefficients of variation less than $10 \%$ in the range $5-45 \mathrm{mg} / 1$ thyroxine binding globulin and $20-100 \mu \mathrm{g} / 1$ for total thyroxine) performed similarly to the in-house methods in the differentiation of eu-, hypo- and hyperthyroidism on the basis of total thyroxine/thyroxine binding globulin quotients. Although statistically significant differences often occurred in comparisons of the in-house method with the luminescence enhanced enzyme immunoassays, these only gave rise to thyroid status differences in two cases out of 273 , where the in-house method gave a hyperthyroid, the luminescence enhanced enzyme immunoassay a euthyroid answer, when taken from the total thyroxine/thyroxine binding globulin quotients.

The luminescence enhanced enzyme immunoassays performed as well as the in-house methods, and quality assessment data were comparable with their radioimmunological counterparts.

\section{Introduction}

The trend towards the increased use of non-radioisotopic immunoassays continues; the present article describes the comparison of a commercially available luminescence enhanced enzyme immunoassay (Amersham International) with an in-house immunoluminometric assay (1) for the determination of thyroxine binding globulin in serum. In order to assess thyroid status, thyroxine values were also measured, using both luminescence enhanced enzyme immunoassay (Amersham International) and fluorescence polarisation immunoassay (Abbott Laboratories). Thyrox- ine/thyroxine binding globulin quotients were then constructed.

A euthyroid reference range was established on 108 blood donors with normal thyroid parameters (basal thyrotropin, thyroxine and triiodothyronine) and normal aminotransferases and $\gamma$-glutamyl transpeptidase levels. Forty two blood donors who did not fulfil these criteria were excluded from the group.

Patients were selected from the dialysis clinic, as it is known that dialysis patients often have anomalous results due, amongst other things, to dysproteinaemia 
(2). Other experimental groups included tumour bearers and non-selected patients attending the thyroid outpatient clinic.

The aim of the study was to see whether the new kit was able to assess thyroid status, when used in conjunction with other relevant thyroid parameters.

\section{Materials and Methods}

The luminescence enhanced immunoassay kits for total thyroxine and thyroxine binding globulin (Amerlite) were donated by Amersham-Buchler, Braunschweig, D. The fluorescence-polarisation immunoassay for total thyroxine (Abbott TDx) was from Abbott, Diagnostics Wiesbaden-Delkenheim, D.

The immunoluminometric assay for thyroxine binding globulin was the in-house assay and has been described elsewhere (1).

The Amerlite Assays were set up manually and were processed on the Amerlite washer and measuring/processing unit (tab. 1 a $+1 b)$.

The Abbott TDx Assay was performed according to the manufacturer's instructions (tab. 1 c) and the immunoluminometric assay was performed as described in table $1 \mathrm{~d}$. Patient samples were obtained from the routine laboratory of this department and from the blood bank of the hospital.

Tab. 1 a. Flow scheme of the Amerlite - TBG Assay

$10 \mu \mathrm{l} \mathrm{sample/standard} \mathrm{in} \mathrm{antibody} \mathrm{coated} \mathrm{well,}$ $100 \mu \mathrm{l}$ labelled antigen (peroxidase),

$100 \mu \mathrm{l}$ assay reagent buffer.

Incubate 30 minutes at $37^{\circ} \mathrm{C}$,

wash, add $250 \mu$ l signal reagent to each well,

wait 5 minutes, measure in

Amerlite luminometer and await results

Tab. 1 b. Flow scheme of the Amerlite $\mathrm{TT}_{4}$ Assay

$10 \mu \mathrm{l} \mathrm{sample/standard} \mathrm{into} \mathrm{antibody} \mathrm{coated} \mathrm{well,}$ $100 \mu \mathrm{l}$ labelled antigen (peroxidase),

$100 \mu \mathrm{l}$ assay reagent buffer.

Incubate 60 minutes at $37^{\circ} \mathrm{C}$,

wash and add $250 \mu$ l signal reagent,

wait 5 minutes, measure and await results.

Tab. 1 c. Flow scheme of the Abbott TDx $\mathrm{TT}_{4}$ Assay

$100 \mu \mathrm{l}$ sample in sample cup.

Insert with control sera and reagents into analyser; await results.

Tab. 1 d. Flow scheme of the Immunolumetric Assay for thyroxine binding globulin

$25 \mu$ l sample/standard (1:250 dilution),

$200 \mu \mathrm{l}(\mathrm{ABEN}-\mathrm{H})$-labelled antibody to thyroxine binding globulin,

1 anti-thyroxine binding globulin coated ball.

Incubate 60 minutes in rotator $\left(170 \mathrm{~min}^{-1}\right)$,

wash with $2 \times 5 \mathrm{ml} 0.25 \mathrm{ml} / 1$ Tween 20 ,

transfer ball to measuring cuvette, add catalyst, initiate light reaction with alkaline peroxide and integrate signal over $4 \mathrm{~s}$.

ABEN-H $=\mathrm{N}$-(4-aminobutyl)-N-ethylisoluminol hemisuccinamide
For comparison, the thyroxine binding globulin standards from the Amerlite Kit were used in both Amerlite and ILMA methods.

Patients were divided into 3 groups - thyroid outpatients $(n=165)$, tumour bearers $(n=44)$ (clinically or surgically confirmed cases) and dialysis clinic $(n=84)$. Reference ranges were set up from 108 blood donor sera.

Non-parametric statistics were used throughout as certain data were not normally distributed (mean/median ratio $0.95-1.05$ by unimodal distribution). Results were expressed as percentiles and the mid-range as the median. The mean/median ratio was used to express skewness. The Wilcoxon signed rank-test with C-Alpha calculation was used for paired data, the Mann Whitney U-Test for non-paired data. Correlations were calculated from normal or near-normally distributed data.

\section{Results}

The results are presented, as far as possible, in tabular form to save space and give an easy-to-read format.

Sera which were lipaemic, haemolytic or icteric were noted to check the effects of these conditions on the assays. As no difference in results by different methods was seen, no special statistical treatment of such sera was made. The total thyroxine/thyroxine binding globulin quotient for serum is calculated from total thyroxine in $\mu \mathrm{g} / 1$ and thyroxine binding globulin in $\mathrm{mg} / \mathrm{l}$. Detailed clinical data on the patient groups has been kept to a minimum, especially for the heterogeneous thyroid-outpatient group. It must be noted that the median age of the experimental groups is different from the reference group of blood-donors. This was practically unavoidable without extensive screening of all groups. This has no effect on the total thyroxine/thyroxine binding globulin quotients, which have been reported to remain constant throughout life (3).

\section{Age distribution in the different groups}

Table 2 shows the age ranges and relevant percentiles in each of the experimental groups.

Tab. 2. Age distribution in the different groups

\begin{tabular}{lllll}
\hline Parameter & $\begin{array}{l}\text { Blood } \\
\text { donors }\end{array}$ & Thyroid & Dialysis & $\begin{array}{c}\text { Tumour } \\
\cdots\end{array}$ \\
\hline No. in group & 108 & 165 & 84 & 44 \\
$\begin{array}{l}\text { Age distribution } \\
\text { (years) }\end{array}$ & & & & \\
2.5 Percentile & 18 & 22 & 24 & 36 \\
16 & 21 & 46 & 45 & 46 \\
50 (Median) & 28 & 66 & 62 & 65 \\
84 & 47 & 79 & 77 & 81 \\
97.5 & 63 & 87 & 80 & 89 \\
Mean age (years) & 33 & 63 & 60 & 65 \\
Mean/Median & 1.17 & 0.949 & 0.970 & 0.996 \\
\hline
\end{tabular}


Tab. 3. Distribution of thyroxine binding globulin values Amerlite and Comparison method in the 4 Groups.

1. Amerlite TBG (mg/l)

\begin{tabular}{lcccc} 
Percentile & $\begin{array}{c}\text { Blood } \\
\text { donors }\end{array}$ & Dialysis & Tumour & Thyroid \\
\hline 2.5 & 12.2 & 12.4 & 18.0 & 12.9 \\
16 & 18.7 & 14.0 & 23.0 & 16.4 \\
50 (median) & 24.9 & 17.2 & 27.0 & 20.6 \\
84 & 34.5 & 23.0 & 32.8 & 26.0 \\
97.5 & 53.3 & 30.9 & 45.0 & 34.9 \\
Mean & 27.0 & 19.1 & 28.5 & 21.3 \\
Mean/median & 1.09 & 1.12 & 1.06 & 1.03 \\
No. in group & 108 & 85 & 44 & 165 \\
\hline
\end{tabular}

\section{ILMA TBG (mg/l)}

\begin{tabular}{lccc} 
Percentile & $\begin{array}{c}\text { Blood } \\
\text { donors }\end{array}$ & Dialysis & Thyroid \\
\hline 2.5 & 11.3 & 12.7 & 14.0 \\
16 & 15.3 & 14.2 & 18.2 \\
50 (median) & 22.0 & 17.3 & 24.0 \\
84 & 30.7 & 26.4 & 28.0 \\
97.5 & 49.0 & 42.1 & 35.0 \\
Mean & 24.0 & 20.2 & 23.9 \\
Mean/median & 1.09 & 1.16 & 0.996 \\
No. in group & 108 & 85 & 165 \\
\hline
\end{tabular}

Distribution of thyroxine binding globulin and total thyroxine values

Table 3 shows the distribution of the thyroxine binding globulin values in both methods. Table 4 shows the same data for the total thyroxine serum concentrations.
Tab. 4. Distribution of total thyroxine values in the different groups

\begin{tabular}{lcccc} 
1. Amerlite & $\mathrm{TT}_{4}(\mu \mathrm{g} / \mathrm{l})$ & & & \\
Percentile & $\begin{array}{c}\text { Blood } \\
\text { donors }\end{array}$ & Dialysis & Tumour & Thyroid \\
\hline 2.5 & 41 & 21 & 21 & 43 \\
16 & 47 & 38 & 51 & 57 \\
50 (median) & 59 & 52 & 68 & 80 \\
84 & 74 & 72 & 83 & 95 \\
97.5 & 85 & 105 & 102 & 136 \\
Mean & 61 & 55 & 67 & 80 \\
Mean/median & 1.02 & 1.06 & 0.998 & 1.00 \\
No. in group & 108 & 85 & 44 & 105 \\
\hline
\end{tabular}

\section{Abott TDx $\mathrm{TT}_{4}(\mu \mathrm{g} / \mathrm{l})$}

\begin{tabular}{lcc} 
Percentile & $\begin{array}{l}\text { Blood } \\
\text { donors }\end{array}$ & Thyroid \\
\hline 2.5 & 37 & 50 \\
16 & 52 & 64 \\
50 (median) & 68 & 80 \\
84 & 83 & 103 \\
97.5 & 100 & 144 \\
Mean & 69 & 83 \\
Mean/median & 1.03 & 1.04 \\
No. in group & 108 & 165
\end{tabular}

\section{Correlation between both methods}

The correlation between the thyroxine binding globulin and total thyroxine concentrations in the relevant groups is given in table 5. Table 6 shows the nonparametric statistics for the differences in thyroxine binding globulin and total thyroxine concentrations found in the experimental groups as compared with the blood donors.

Tab. 5. Correlation between routine assays and Amerlite assays.

( $x=$ routine, $y=$ Amerlite where not stated otherwise)

\begin{tabular}{|c|c|c|c|c|c|c|c|c|}
\hline Group & $\mathbf{n}$ & $\mathbf{r}$ & a1 & b1 & a2 & b2 & pt & sig \\
\hline \multicolumn{9}{|c|}{ 1. Thyroxine binding globulin } \\
\hline $\begin{array}{l}\text { Blood donors } \\
\text { Dialysis') } \\
\text { Thyroid }\end{array}$ & $\begin{array}{r}108 \\
85 \\
164\end{array}$ & $\begin{array}{l}0.85 \\
0.69 \\
0.85\end{array}$ & $\begin{array}{l}0.96 \\
5.82 \\
2.13\end{array}$ & $\begin{array}{l}0.85 \\
0.66 \\
0.80\end{array}$ & $\begin{array}{l}6.67 \\
6.45 \\
4.73\end{array}$ & $\begin{array}{l}0.85 \\
0.72 \\
0.90\end{array}$ & $\begin{array}{l}4.47 \\
1.62 \\
11.2\end{array}$ & $\begin{array}{l}\text { s } \\
\text { ns } \\
\text { s }\end{array}$ \\
\hline \multicolumn{9}{|c|}{ 2. Total thyroxine } \\
\hline $\begin{array}{l}\text { Blood donors } \\
\text { Thyroid }\end{array}$ & $\begin{array}{l}108 \\
105\end{array}$ & $\begin{array}{l}0.75 \\
0.91\end{array}$ & $\begin{array}{l}21.1 \\
11.0\end{array}$ & $\begin{array}{l}0.77 \\
0.84\end{array}$ & $\begin{array}{l}9.47 \\
3.90\end{array}$ & $\begin{array}{l}0.97 \\
0.99\end{array}$ & $\begin{array}{l}6.37 \\
1.93\end{array}$ & $\begin{array}{l}\text { s } \\
\text { ns }\end{array}$ \\
\hline \multicolumn{9}{|c|}{ 3. Amerlite $\mathrm{TBG} 5 \mathrm{~min}$ v $25 \mathrm{~min}$} \\
\hline & 84 & 1.00 & 0.09 & 1.07 & 0.09 & 0.92 & -7.93 & $\mathbf{s}$ \\
\hline \multicolumn{8}{|c|}{ 4. Amerlite $\mathrm{TT}_{4} 2 \mathrm{~min} v 12 \mathrm{~min}$} & $s$ \\
\hline
\end{tabular}

Key:

The regression lines represent the equations $y=a 1+b 1 x$ and $x=a 2+b 2 y$.

pt - paired t-value.

sig - significance, $n s=$ not significant, $s=$ significant.

1) with an alternative pair of antibodies, the anomalous results were not longer present, the regression data being as follows for the dialysis patients: $\mathrm{n}=85, \mathrm{r}=0.82, \mathrm{a} 1=3.27, \mathrm{~b} 1=0.81, \mathrm{a} 2=2.79, \mathrm{~b} 2=0.91, \mathrm{pt}=1.04$, ns. 
Tab. 6. Comparison of groups using the Mann-Whitney U-test with $\mathrm{z}$-transformation

\section{TBG Amerlite}

Blood donors $v$ Dialysis

Blood donors $\vee$ Thyroid

$-\mathrm{z}=6.30(\mathrm{~s}) \mathrm{p}<0.01$

Blood donors $v$ Tumour

$-\mathrm{z}=3.52(\mathrm{~s}) \quad \mathrm{p}<0.01$

$-\mathrm{z}=-1.74$ (ns) $\mathrm{p}>0.05$

2. $\mathrm{TT}_{4}$ Amerlite

Blood donors $v$ Dialysis

Blood donors $v$ Thyroid

$-\mathrm{z}=3.01(\mathrm{~s}) \mathrm{p}=0.01$

Blood donors $v$ Tumour

$-\mathrm{z}=-5.41(\mathrm{~s}) \quad \mathrm{p}<0.01$

$-\mathrm{z}=-2.28(\mathrm{~s}) \mathrm{p}<0.05$

3. TBG ILMA

Blood donors $v$ Dialysis $\quad-z=2.96 \quad(p=0.01)$

Blood donors $v$ Thyroid $-z=-1.45$ (ns) $(\mathrm{p}>0.05)$

4. $\mathrm{TT}_{4}$ Abbott

Blood donors v Thyroid $-z=-4.39$ (s) $\quad(p<0.01)$

$s$ - significant difference

ns - no significant difference

\section{Thyroxine/thyroxine binding globulin}

Thyroxine/thyroxine binding globulin quotients were calculated because no "free thyroxine" determination was available from either Abbott or Amersham which used a non-radioisotopic label. Table 7 shows the distribution of thyroxine/thyroxine binding globulin ratios, calculated as stated in the materials and methods section above.

Tab. 7. Distributions of total thyroxine/thyroxine binding globulin

\section{a. Amersham}

Parameter

Blood donors

Dialysis Tumour Thyroid

\begin{tabular}{lrrrr}
\hline No. of data & \multicolumn{1}{l}{108} & \multicolumn{1}{l}{84} & \multicolumn{1}{l}{44} & \multicolumn{1}{l}{105} \\
2.5 Percentile & 1.00 & 1.65 & 0.83 & 1.90 \\
16 & 1.68 & 2.14 & 1.92 & 2.72 \\
50 (median) & 2.33 & 2.89 & 2.40 & 3.68 \\
84 & 3.20 & 3.76 & 2.86 & 4.56 \\
97.5 & 5.82 & 4.94 & 3.70 & 5.65 \\
& 2.49 & 3.00 & 2.41 & 3.70 \\
Mean & 1.07 & 1.04 & 1.00 & 1.00 \\
\hline
\end{tabular}

b. ILMA/Abbott

\begin{tabular}{lccc} 
& \multirow{2}{*}{ Blood donors } & \multicolumn{2}{c}{ Thyroid } \\
\cline { 3 - 4 } Parameter & & $\mathrm{a}$ & $\mathrm{b}$ \\
\hline No. of data & 108 & 165 & $105^{*}$ \\
2.5 Percentile & 0.98 & 2.27 & 2.15 \\
16 & 1.90 & 2.62 & 2.51 \\
50 (median) & 3.28 & 3.40 & 3.27 \\
84 & 4.40 & 4.47 & 4.41 \\
97.5 & 5.68 & 6.04 & 5.92 \\
Mean & 3.25 & 3.60 & 3.43 \\
Mean/median & 0.99 & 1.06 & 1.05 \\
\hline
\end{tabular}

* Using the same 105 patients as in the Amersham kit.
Table 8 shows the statistical differences in the thyroxine/thyroxine binding globulin ratios, expressed against the blood donors as controls. From table 7, the reference range of the thyroxine/thyroxine binding globulin ratio in the Amerlite system is from 1.005.82 (95\% confidence-limits) and for the ILMA/Abbott combination $1.20-5.68$. Table' 9 shows the coincidence of the thyroxine/thyroxine binding globulin ratio in both methods using the reference ranges above. From this table it can be seen that the discrimination of both methods is similar for the thyroid outpatients group, and that in both unselected tumour and dialysis patients, a euthyroid status is predominant according to the total thyroxine/thyroxine binding globulin ratios. The numerical value of the total thyroxine binding globulin ratios was significantly different in both methods as can be seen in table 10 , but this did not affect the classification into eu-, hypoor hyperthyroid groups.

Tab. 8. Comparison of total thyroxine/thyroxine binding globulin ratios on the different groups as compared with the reference group. Using the Mann-Whitney U-test with $\mathrm{z}$-transformation

a) Amersham

Blood donors v Dialysis $z=-3.85$ (s) $p<0.01$

Blood donors $v$ Thyroid $z=-7.18$ (s) $p<0.01$

Blood donors $v$ Tumour $z=-0.06$ (ns) $p>0.05$

b) ILMA/Abbott

a. Blood donors $v \quad z=-1.57(n s) p>0.05(n=165)$ Thyroid

b. ${ }^{*}$ ) Blood donors $v \quad z=-0.80(n s) p<0.05(n=105)$ Thyroid

*) on the same 105 patients as measured with the Amersham assays.

Tab. 9. Coincidence of total thyroxine/thyroxine binding globulin ratios in the different experimental groups

a) Amersham

Dialysis Thyroid Tumour $\mathrm{n}=84 \quad \mathrm{n}=105 \quad \mathrm{n}=44$

\begin{tabular}{lrrr}
\hline a Hypothyroid $(<1.00)$ & 1 & 1 & 1. \\
b Euthyroid $(1.00-5.82)$ & 83 & 102 & 43 \\
c Hyperthyroid $>5.82$ & 0 & 2 & 0
\end{tabular}

b) ILMA/Abbott $\quad-\quad \begin{aligned} & \text { *) } \\ & \text { Thhyroid } \\ & n=105\end{aligned}$

a Hypothyroid $(<1.2)$

b Euthyroid $(1.2-5.68)$

c Hyperthyroid

100

*) For comparison, the same 105 patients were measured in both assays. 
Tab. 10. Statistical comparison of total thyroxine/thyroxine binding globulin quotient of the Amersham and inhouse methods

\begin{tabular}{ll}
\hline ILMA & $=x$ \\
Amersham & $=y$ \\
Blood donors & $(n=108) c_{\alpha}=5.62 \mathrm{p}<0.01$ \\
Thyroid & $(n=105) c_{\alpha}=3.98 \mathrm{p}<0.01$ \\
Correlation & $\mathrm{y}=\mathrm{a}+\mathrm{bx}$ \\
Blood donors & $-\mathrm{n}=108$ \\
& $\mathrm{r}=0.762$ \\
& $\mathrm{ayx}=0.468$ byx $=0.62$ \\
& $\mathrm{axy}=0.927$ bxy $=0.93$ \\
& $\mathrm{n}=105$ \\
Thyroid & $\mathrm{r}=0.723$ \\
& $\mathrm{ayx}=1.21$ byx $=0.726$ \\
& $\mathrm{axy}=0.753$ byx $=0.722$ \\
\hline
\end{tabular}

\section{Quality assessment}

The intra- and inter-assay coefficients of variation are shown in table 11 for the Amerlite kits. These were determined in the usual way i.e. with 20 measurements of the control serum in one assay, or from duplicate measurements of the serum in 20 consecutive assays. The interassay coefficient of variation of the Abbott $\mathrm{TT}_{4}$ assay was $8.7 \%$ at $88 \mu \mathrm{g} / 1$ and $8.5 \%$ at $25.4 \mathrm{mg} / 1$ for the TBG ILMA. Intraassay coefficients of variation were not calculated for the Abbott $\mathrm{TT}_{4}$ assay as samples were run without replicates. The mean intraassay coefficient of variation for the TBG ILMA in the range $10-50 \mathrm{mg} / 1$ was $5.3 \%$, these figures being derived from precision profiles in which 672 values were taken from 34 assays.

Lower detection limits of the Amerlite TBG and $\mathrm{TT}_{4}$ kits

The lower detection limits of the assays were determined, despite the fact that these were clinically irrelevant. The thyroxine binding globulin assay had a lower detection limit below $3 \mathrm{mg} / 1$ and the total thyroxine assay below $15 \mu \mathrm{g} / \mathrm{l}$. The data in table 11 indirectly support these figures. These data show that both assays are suited for routine use, even in the detection of radically reduced thyroxine binding glob= ulin concentrations found in hereditary cases of thyroxine binding globulin deficiency.

\section{Discussion}

The continuous introduction of non-radioisotopic methods into in-vitro thyroid diagnosis, using both open and closed systems, makes an evaluation of such methods necessary, especially with respect to clinical usefulness.
Tab. 11. Quality control parameters for the Amerlite system

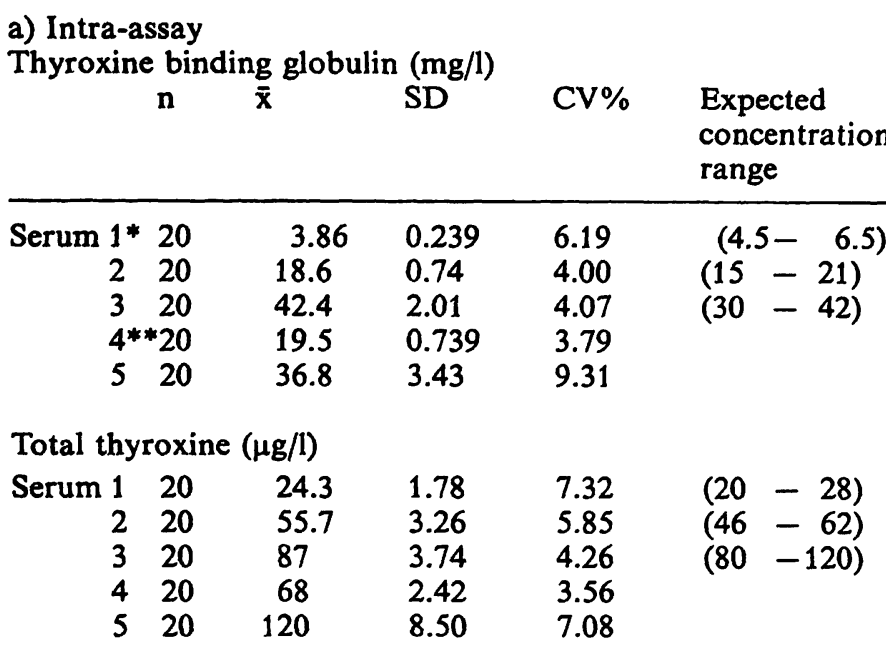

b) Inter-assay

Thyroxine binding globulin $(\mathrm{mg} / \mathrm{l})$

$\begin{array}{rcccc}\text { Serum 1 } & 20 & 5.73 & 0.568 & 9.91 \\ 2 & 20 & 18.2 & 1.28 & 7.01 \\ 3 & 20 & 43.8 & 3.28 & 7.55\end{array}$

Total thyroxine $(\mu \mathrm{g} / \mathrm{l})$

$\begin{array}{rrrrr}\text { Serum 1 } & 20 & 23.9 & 2.20 & 9.22 \\ 2 & 20 & 52.6 & 4.29 & 8.15 \\ 3 & 20 & 92.0 & 4.71 & 5.12\end{array}$

* Serum 1-3 were pool sera supplied with the kits.

** Serum $4+5$ were single patient sera from the routine laboratory

With the introduction of TBG, the Amerlite system now has a full thyroid programme consisting of thyrotropin, triiodothyronine, thyroxine binding globulin and thyroxine, thus allowing surveillance at the pituitary, thyroid and peripheral levels.

Although the in-house and Amersham methods sometimes gave different analytical values, the clinical interpretation of the results - as reflected in tables 7-9 was similar.

The lower detection limits of the assay were excellent (see tab. 11 for indirect evidence) and are fully comparable with those of radioimmunological methods. The quality control data (tab. 11) shows the "alternative methods" also to be equivalent to the best radioimmunological ones.

The total thyroxine/thyroxine binding globulin quotients in the euthyroid range were comparable to those obtained by most other published methods (3).

The absence of large numbers of hypo- or hyperthyroid patients may be due to the fact that the majority of patients attending the outpatient clinic were under medication for their thyroid disorder. The limited value of in-vitro tests in such cases has been discussed 
at length, with arguments expressed against unneccessary in-vitro tests $(4,5)$ and in favour $(6)$ of such testing. This point will not be further discussed here, as it lines outside the scope and aims of the study.

Until the measurement of "free thyroxine" has been standardised with respect to methodology and reference ranges, there is still a valid argument for the construction of total thyroxine/thyroxine binding globulin quotients to assess thyroid status (7-9).

Since much in-vitro testing is performed in laboratories where the patient is unknown, the present study has concentrated on the quality of the tests, rather than details about specific groups of patients, for example with "non-thyroidal illness“, or the question of whether in-vivo or in-vitro heparin affects the results. It is important to note that lipaemia, haemolysis and hyperbilirubinaemia do not adversely affect results, when compared with the routine methods used in this study.

\section{References}

1. Gadow, A., Wood, W. G. (1984) Solid phase luminescence immunoassays for thyroid parameters. In: Analytical Applications of Bioluminescence and Chemiluminescence (Kricka, L. J. et al., eds.) Academic Press, London, Orlando, pp. 209-213.

2. Wood, W. G., Marschner, I. \& Scriba, P. C. (1979) Horm. Met. Res. 11, 309-317.

3. Rudorff, K. H., Herrmann, J. \& Krüskemper, H. L. (1981) Intern. Welt. 10, 102-108.

4. Fraser, W. D., Biggart, E. M., O'Reilly, D. S., Gray, H. W., McKillop, J. H. \& Thomson, J. A. (1986) Brit. Med. J. $293,808-810$.
The light signal of the Amersham assays was stable for relatively long periods of time, thus allowing delayed or repeated measurements of samples.

Although the numerical values were statistically different (see tab. 8), this was only marginally relevant and was due to curve-fitting rather than to differential deterioration of samples. As shown in a prior communication from this laboratory (10), in which a luminescence enhanced enzyme immunoassay for carcinoembryomic antigen was evaluated, this type of assay is ready for routine use and offers a real routine alternative to radioimmunological methods.

\section{Acknowledgement}

The authors wish to thank Frau Christel Rodust for typing the manuscript, as well as Amersham-Buchler, Braunschweig, for supplying the luminescence enhanced immunoassay kits.
5. Pickardt, C. R. \& Horn, K. (1986) Internist 27, 584-590.

6. Wenzel, K. W. (1987) Dtsch. Med. Wochenschr. 112, 81.

7. Mahlstedt, J. (1984) Akt. Endokr. Stoffw. 5, Sonderheft 1, $36-43$.

8. Vermaak, W. J. H., Kalk, W. J. \& Zakolski, W. J. (1983) Lancet $i, 1373-1375$.

9. Bienhaus, G., Rokos, H. \& Steinmaus, H. (1982) Nucl. Med. 21, 184-185.

10. Wood, W. G. (1987) J. Clin. Chem. Clin. Biochem. 25, $699-703$.

Priv.-Doz. Dr. W. G. Wood

Klinik f. Innere Medizin

Med. Univ. Lübeck

Ratzeburger Allee 160

D-2400 Lübeck 1 